\title{
15 | Opening up or closing down? Analysis, participation and power in the social appraisal of technology
}

\author{
ANDY STIRLING
}

\section{Participation and analysis in social appraisal}

Not without some irony, burgeoning discourses on participation have become a key theme in the globalizing governance of science and technology. As Leach and Scoones discuss (Chapter 2), experience in the North and the South is convergent in several ways. In both settings, the language of 'inclusion', 'engagement' and 'deliberation' is moving into successive political arenas. Beginning in the planning and implementation of specific projects and programmes, a wave of increasing attention to participation is moving through more general frameworks for environmental regulation and the governance of 'technological risk'. New political arenas look set to open up as 'upstream' processes of knowledge production, technological innovation and institutional commitment to technology begin to acquire their own distinctive discourses on participation.

This emergence of new avenues for social agency in the governance of science and technology is presaged in earlier academic trends. Despite the cross-disciplinary differences, understandings of society-technology relationships arising in philosophy, economics, history and social studies paint a common picture (Williams and Edge 1996). Earlier deterministic, linear notions of 'progress' have given way to a picture of contingency (David 1985), social shaping (Bijker 1995), momentum (Hughes 1983), lock-in (Arthur 1989), autonomy (Winner 1977) and 'entrapment' (Walker 2000). The form and direction taken by our science and technology are no longer seen as inevitable and monolithic, awaiting 'discovery' in nature. Instead they are increasingly recognized as being open to shaping by individual creativity, collective ingenuity, cultural priorities, institutional interests, stakeholder negotiation and the exercise of power. The irony is thus intensified. Just at a time when globalization seems to render the governance of science and technology more obscure, remote and inaccessible, so we begin to appreciate the inherent openness to the exercise of human agency and - potentially - to deliberate social choice.

Even if 'deliberate' only from the point of view of incumbent interests, the message is that the directions taken by scientific and technological 
developments have always effectively been subject to social choice. These choices have, in turn, always been informed by more specific processes (whether explicit or implicit, broad or narrow) of social appraisal. In this sense, then, the advent of new participatory discourses might be seen as an incipient move towards the broadening, diversification and enriching of established practices for the social appraisal of science and technology.

From an evaluative perspective associated with participatory discourses, we are faced with a stark dichotomy. On the one hand (so it goes), there are the established, narrow, rigid, quantitative, opaque, exclusive, expert-based, analytically rigorous procedures, tending to privilege economic considerations and incumbent political and commercial interests (Collingridge 1980; Flyvbjerg 1998; Wynne 1975). Broadly, these may be seen to include approaches such as risk and cost-benefit analysis, technology and lifecycle assessment, as well as Delphi methods and expert advisory committees. On the other hand (so it goes), there are the new, relatively unconstrained, qualitative, sensitive, inclusive, transparent, deliberative, democratically legitimate processes, tending to offer greater emphasis on otherwise marginal issues and interests (such as environmental protection, public health and distributional fairness) (Fischer 1990; Irwin 1995; Sclove 1995). Examples here might be stakeholder forums, consensus conferences, citizens' panels, focus groups and deliberative polls.

There can be no doubting the substance and salience of this dichotomy in many instances. Whether as a cause or as an effect, the emergence of new participatory practices is often associated with increasing acknowledgements of, aspirations towards (and sometimes even achievements in) the greater and more deliberate exercise of a wider agency in the social choice of technology. Many see this as welcome, overdue and insufficient. Yet it is also clear that there exist certain paradoxical, expedient and rhetorical elements in emerging discourses on participation (Irwin 2001b; Levidow 1999; Wakeford 2001). Although the details are complex and diverse, there are some important common questions, which also seem to pervade both Northern and Southern settings. Exactly why are we seeing this increasing interest in participation? Which rationales and motivations are more important for different policy actors? Are there commonalities, synergies or tensions that cross-cut the apparently simple dichotomy? Are there important similarities or differences in the ways in which these styles engage with institutional power? What are the broader social and political implications?

Amid the intensive high-profile activity and discussion, answers to these kinds of question are usually given in terms of the dichotomy itself. Protagonists tend to take up polarized positions, with others constructing intermediate or synthetic positions, which are equally framed according 
to the analysis/participation dichotomy. There seems curiously little critical attention to the validity and utility of the conceptual dichotomy itself. In particular, there seems to be a neglect of important transcendent and cross-cutting issues, which divide analytic and participatory approaches alike. Some of these may in some circumstances be of greater importance than the dominant distinction between the 'analytic' and 'participatory' categories themselves.

Drawing mainly on experience in the science policy and risk regulation fields in Northern settings, this chapter offers a brief survey of a few key issues. First, it reviews three distinct perspectives on the role of participation in social appraisal and examines the contrasting attitudes to power that are embodied in each. This is then taken as a basis for exploring the extent to which both participatory and analytic approaches raise similar issues of framing and justification. The argument is developed that there exists a crucial general feature in the design and conduct of social appraisal that is equally relevant to participatory and analytic approaches alike, but which remains unduly neglected by each. This concerns whether it is the aim of social appraisal to 'open up' or 'close down' wider policy discourses. The discussion closes by querying the implications of this distinction for globalizing processes of governance in the social choice of technology.

\section{Empowerment, quality and trust}

In considering the range of imperatives, rationales and motivations bearing on participation in the social appraisal of science and technology, a useful distinction may be drawn between three types of perspective: normative, instrumental and substantive (Fiorino 1989; Fineberg 1996). From a normative view, participation is just the right thing to do. From an instrumental perspective, it is a better way to achieve particular ends. In substantive terms, it leads to better ends.

Normative commitments in social appraisal may take a number of forms. Curiously value-laden notions of 'value-free analysis' and emotive appeals to 'sound science' are a common defence of established expert procedures (Byrd and Cothern 2000). In the case of participation, the normative imperatives rest on principles of democratic emancipation, equity, equality and social justice. Invoking authorities such as Rawls (1971) and Habermas (1975), the formal rationale here hinges on a commitment to the empowerment of citizens (especially those with marginal or excluded interests), rather than dominant institutions or elite social groups. At minimum, this rests on the idea that contemporary societies should - as an end in and of itself - be engaging all relevant constituencies in making decisions about scientific and technological choices. 